\title{
Do global ao contexto nacional: evolução da política ambiental brasileira
}

\section{Leandro Muniz Barbosa da Silva ${ }^{1}$, , Julio Pergentino da $\operatorname{Silva}^{2}$ e Maria Alice de Lira Borges ${ }^{1}$}

1Universidade Federal de Pernambuco. Programa de Pós-Graduação em Desenvolvimento e Meio Ambiente. Av. Prof. Moraes Rego, 1235. Cidade Universitária. Recife-PE, Brasil (CEP 50670-901). *E-mail: leandrombsilva1@gmail.com.

2Universidade Estácio de Sá. Curso de Relações Internacionais. Rua Padre Bernardino Pessoa, 512. Boa Viagem. Recife-PE, Brasil (CEP 51020-210).

Resumo. Apesar do avanço brasileiro no tratar das questões ambientais visando à preservação e conservação da sua sociobiodiversidade, os mecanismos políticos criados para a redefinição do controle dos recursos ambientais no território do país tornam-se insuficientes frente a um contexto internacional de avanço do desenvolvimento e da crise política, socioeconômica e ambiental que assola o país, o que estimula a exploração dos recursos ambientais - desmatamento, extinção de espécies, perda de serviços ambientais e mudanças no clima. O objetivo da pesquisa foi discutir a influência da política internacional na evolução das políticas ambientais do Brasil e os retrocessos em decorrência de ações governamentais. Com este intuito, foram utilizadas as técnicas da pesquisa bibliográfica e análise de conteúdo para tratamento e interpretação dos dados obtidos. Foi constado um grande avanço das políticas ambientais do país ao longo das últimas cinco décadas, adequando-se às exigências mundiais estabelecidas em conferências de países integrantes da Organização das Nações Unidas (ONU), elevando o Brasil de um posicionamento bissetorial para multissetorial no tratar das questões ambientais. Contudo, esse avanço vem sendo colocado em risco devido a medidas governamentais que visam a enfraquecer a política ambiental brasileira, proporcionando maior flexibilidade para empreendedores nacionais e internacionais explorarem os recursos ambientais do país.

Palavras-chave: Relações internacionais; Recursos ambientais, Governança.

Abstract. From global to national context: Evolution of Brazilian environmental policy. Despite Brazil's progress in addressing environmental issues aimed at preserving and conserving its socio-biodiversity, the political mechanisms created to redefine the control of environmental resources in the country's territory become insufficient in the face of an international context of economic development and
Recebido

01/08/2019

Aceito

13/11/2019

Disponível on line 13/11/2019

Publicado

31/12/2019

Acesso aberto

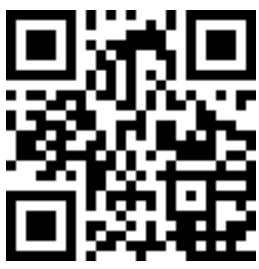

ORCID

(C) 0000-0002-7057-5913

Leandro Muniz

Barbosa da Silva

(D) 0000-0003-4183-5365

Julio Pergentino da

Silva

(D) 0000-0002-8171-3103

Maria Alice de Lira

Borges 
socioeconomical, political and environmental crisis advancement that plagues the country, which encourages the exploitation of environmental resources - deforestation, extinction of species, loss of environmental services and climate change. The objective of the research was to discuss the influence of international politics in the evolution of the environmental politics of Brazil and setbacks due to government actions. For this reason, the techniques of bibliographic research and content analysis were used for treatment and interpretation of the obtained data. There has been a great advance in the country's environmental policies over the last five decades, adapting to the global requirements established in conferences of member countries of the United Nations (UN), elevating Brazil from a bisectoral to multisectoral approach in addressing environmental issues. However, this advance has been put at risk due to government measurements aimed at weakening Brazilian environmental policy, providing greater flexibility for national and international entrepreneurs to exploit the country's environmental resources.

Keywords: International relations; Environmental resources; Governance.

\section{Introdução}

Em setembro de 1962, foi publicado o livro "Primavera Silenciosa", escrito pela Bióloga Marinha, a norte-americana Rachel Carson. O livro trouxe aos olhos do mundo o impacto que as indústrias químicas de inseticidas e outros derivados sintéticos, causavam ao meio ambiente. A pulverização aérea contaminava os pássaros ocasionando efeitos negativos aos ciclos ecossistêmicos, resultando em problemas reprodutivos e altos índices de mortalidade (Carson, 2010).

Uma década depois, no ano de 1972, aconteceu na Suécia, a Conferência de Estocolmo, a primeira conferência das Nações Unidas sobre questões ambientais, que teve como objetivo denunciar a degradação da Natureza até aquele momento. Na ocasião, estavam presentes chefes de estados e representantes de 113 países. Durante o encontro, foram elaborados dois importantes documentos norteadores para os ambientalistas e nações comprometidas com os ecossistemas do mundo, a "Declaração Sobre Meio Ambiente Humano" e o "Plano de Ação
Mundial". A conferência foi inspirada pela obra a "Primavera Silenciosa" de Rachel Carson e, a partir daquela convenção, surgiu o conceito de Educação Ambiental como conhecemos atualmente (ONU, 1972).

Outros importantes eventos marcaram a década de 1970 em relação às questões ambientais, com destaque para discussão sobre a finidade dos recursos ambientais mundiais. Desde então, o assunto tornou-se um ícone em todo o mundo e a partir da década de 1980, esse movimento ganhou força, culminando em importantes mudanças culturais e políticas em todo o mundo, despertando o interesse dos governos em cuidar dos ecossistemas para garantir a diversidade dos serviços ambientais que lhes servem.

No Brasil, o movimento ambientalista contribuiu para a promulgação da Lei no 6.938/1981, que dispõe sobre a Política Nacional do Meio Ambiente, objetivando a preservação, melhoria e recuperação da qualidade ambiental propícia à vida, visando a dar condições para desenvolvimento socioeconômico sustentável no país (Brasil, 1981). A partir desse momento, 
outros instrumentos políticos foram criados, a exemplo do Sistema Nacional de Unidades de Conservação do Brasil (SNUC), estabelecido pela Lei no 9.985/2000 (Brasil, 2000), que atualmente garante a proteção de mais de 2 milhões de $\mathrm{km}^{2}$ de unidades de conservação (MMA, 2018).

Apesar do avanço brasileiro no tratar das questões ambientais visando à preservação e à conservação da sua sociobiodiversidade, os mecanismos políticos criados para a redefinição do controle dos recursos ambientais no território do país tornam-se insuficientes frente a um contexto internacional de avanço do desenvolvimento e da crise política, socioeconômica e ambiental que assola o país, o que estimula a exploração dos recursos ambientais, como 0 desmatamento, que contribui para a extinção de espécies, para a perda de serviços ambientais e para as mudanças no clima. Segundo dados da ONU, o valor das trocas comerciais internacionais cresceu seis vezes mais e o seu volume mais que dobrou entre 1980 e 2010 . A intensificação da extração de recursos afeta, principalmente, as nações em desenvolvimento (PNUMA, 2016).

Este contexto provoca pressões e tensões, pois o crescimento econômico demanda o uso cada vez mais intenso dos recursos ambientais. Porém, o tempo da reprodução do capital é infinitamente menor que o tempo da autorecuperação da Natureza. Na última década, uma série de mecanismos foram propostos para tentar regular as tensões internacionais no campo ambiental, estabelecendo uma ordem ambiental internacional (Ribeiro, 1999).

Diante do exposto, o objetivo deste estudo é discutir a influência da política internacional na evolução das políticas ambientais do Brasil e retrocessos em decorrência de ações governamentais.

\section{Metodologia}

A pesquisa desenvolveu-se numa abordagem qualitativa, cujos procedimentos centraram-se na pesquisa bibliográfica e documental. Foi realizada uma análise interpretativa dos dados obtidos buscando entender a relação temporal dos marcos políticos internacionais na evolução das políticas ambientais brasileiras e retrocessos em decorrência de ações governamentais, utilizando a técnica de Análise de Conteúdo que enquanto método reúne um conjunto de técnicas de análise das comunicações que utiliza procedimentos sistemáticos e objetivos de descrição do conteúdo das mensagens. A organização da análise; a codificação de resultados; as categorizações; as inferências; e, por fim, a informatização da análise das comunicações (Bardin, 2009).

\section{Resultados e discussão}

\section{Reflexões sobre política internacional e meio ambiente \\ 0 movimento ambientalista teve} seu surgimento na história do homem pelos teólogos e filósofos, cujo pensamento era fundamentado no foco sobre Deus e a Natureza. O pioneiro a dar início a esse movimento foi Francisco de Assis (1181 a 1226), que obteve reconhecimento mundial como amante dos animais e da Natureza, embasando suas ideias na fraternidade e vivência do homem com respeito às outras criaturas da Natureza (Maia, 2011). Mas só a partir do período pós-revolução industrial e tecnológica (no século XVIII), passou a se intensificar a preocupação com a relação homem e Natureza, pois a chegada das indústrias em larga escala provocou 0 surgimento de indícios evidentes na Natureza de que o ser humano estaria modificando os ambientes naturais de forma demasiada. 
Nas últimas décadas, o aumento na disseminação de informações sobre os problemas ambientais, através da ciência e das mídias sociais, facilitou a divulgação e conscientização a nível global sobre as questões e problemáticas ambientais. Desse modo, tendo conhecimento da existência dos problemas, começou a surgir um despertar ecológico mundial. Principalmente, nas décadas de 1980 e 1990, quando se intensificaram os debates provocados em conferências sobre mudanças climáticas e ambientais, fomentadas por líderes de Estados, movimentos ambientalistas e por grandes pesquisadores dos diversos campos do conhecimento.

A conferência de Estocolmo foi um evento de eximia importância por ser o primeiro encontro de grandes dimensões internacional voltado para temática ambiental que reuniu representantes de diversas nações, para a discussão dos problemas ambientais e da relação entre desenvolvimento e meio ambiente. 0 evento foi realizado em Estocolmo, capital da Suécia, no período de 5 a 16 de junho de 1972 e contou com a participação de 113 países na Conferência das Nações Unidas sobre o Desenvolvimento e Meio Ambiente Humano, conhecida como Conferência de Estocolmo que foi presidida pelo canadense Maurice Strong (ONU, 1972).

A Conferência deu origem a um documento que foi assinado pelos países participantes e teve como um de seus principais desdobramentos a criação do Programa das Nações Unidas para o Meio Ambiente (PNUMA), a primeira agência ambiental global (Paschoaleto et al., 2014).

Apesar da magnitude do evento e da grande contribuição histórica, o que poucos sabem é que o evento foi um tanto atribulado. Havia um clima de tensão entre países do então "primeiro mundo" e países subdesenvolvidos provocados pelo anuncio de dois estudos que criticavam a exploração dos recursos ambientais, indicando o controle populacional e a redução do crescimento econômico como solução para evitar um possível colapso do planeta. 0 primeiro, foram as conclusões do Relatório do Clube de Roma. 0 segundo foi 0 documento base para a Conferência de Estocolmo denominado "Only one Earth: The care and maintenance of a small planet", de responsabilidade de Bárbara Ward e René Dubos, da Organização das Nações Unidas (ONU), que reuniu 70 especialistas do mundo inteiro, reforçando, em grande parte as conclusões do Relatório do Clube de Roma (Viola e Leis, 1995).

$\mathrm{Na}$ época, submerso em um cenário político hostil, o governo brasileiro em sua participação na Conferência de 1972, atuou liderando um bloco de países em desenvolvimento que tinham posição de resistência ao reconhecimento da importância da problemática ambiental. Um dos principais argumentos era de que a principal poluição era a miséria e que se negavam a reconhecer o problema da explosão demográfica (Almeida et al., 2014; Viola e Leis, 1995).

Sob o argumento de que todos tinham direito ao crescimento econômico, o Brasil liderou um bloco de 77 países (do total de 113 países) que defendiam o crescimento econômico a qualquer custo. Em protesto, os representantes do governo brasileiro estenderam uma faixa com os dizeres:

Bem-vindos à poluição, estamos
abertos a ela. O Brasil é um país que
não tem restrições, temos várias
cidades que receberiam de braços
abertos a sua poluição, porque nós
queremos empregos, dólares para o
nosso desenvolvimento (Viola e Leis,
1995).

A faixa ficou famosa pois refletia o pensamento da época de todos terem o direito de crescer economicamente mesmo ocasionando uma grande degradação ambiental. Vale ressaltar, 
que o Brasil estava em pleno "milagre econômico" (Viola e Leis, 1995).

Na década de 1990, foi criada uma série de mecanismos com o objetivo regular as tensões e pressões internacionais pelo uso e controle dos recursos ambientais do planeta, estabelecendo o que Ribeiro (1999), nomeia de "ordem ambiental internacional". Dentre estes mecanismos, destacam-se a Conferência das Nações Unidas sobre o Meio Ambiente (CNUMAD), em 1992, os imperativos ambientais da Organização Mundial de Comércio (OMC), em 1994, e o sistema de qualidade ambiental, série ISO 14000 (ISO, 2015).

Para Ribeiro (1999), os processos de concentração do capital, bem como as novas possibilidades de inovações tecnológicas baseadas no conhecimento genético dos seres vivos ampliou 0 conceito de recurso "natural". No mundo globalizado, ou melhor, na porção do mundo que dispõem de biotecnologia e engenharia genética, todo e qualquer ser vivo e microorganismo é um recurso natural potencial. Isto exigiu maneiras de regular o acesso aos recursos, já que os países que são donos das tecnologias não são os mesmos donos dos recursos genéticos. 0 resultado foi uma complexa teia de relações internacionais, que passa pela CNUMAD, pela OMC e pelo sistema ISO 14000.

É importante destacar que na legislação brasileira, especificamente com base na Política Nacional do Meio Ambiente (PNMA), o meio ambiente é definido por "o conjunto de condições, leis, influências e interações de ordem física, química e biológica, que permite, abriga e rege a vida em todas as suas formas" (Brasil, 1981, art. 3으).

No campo do planejamento e da gestão ambiental, o conceito de ambiente é definido por características variadas, de maneira abrangente e flexível. Reunindo tantos elementos da Natureza como a sociedade, sendo compreendido sob diversas perspectivas, o que vai depender da interpretação do profissional e/ou grupo de pessoas interessadas envolvidas no processo. Sendo assim, a interpretação legal do "ambiente" é de eximia importância para delimitação do alcance dos instrumentos de planejamento e gestão ambiental (Sánchez, 2015).

Nesta perspectiva, aqui 0 conceito de "recursos naturais" será substituído por "recursos ambientais", outrora também poderá ser atribuído o termo "bens ambientais" na tentativa de destituir a monetarização desses elementos de valores imensuráveis.

O objetivo da CNUMAD foi o estabelecimento de acordos internacionais de maneira consensuada entre governos, intuições e sociedade civil de 179 países para mediar as ações humanas de exploração dos recursos ambientais. Durante a conferência conhecida como Rio'92, foram tratados assuntos como: as mudanças climáticas globais e do acesso e manutenção da sociobiodiversidade, utilizando o formato de convenções internacionais (Novaes, 1992).

Como produto desse evento, foram elaboradas declarações e convenções muito importantes que serviram como aporte para criação de uma governança ambiental mundial: a do Rio'92, uma carta de princípios pela preservação e conservação da vida na Terra; a Declaração de Princípios sobre o Uso das Florestas, que estabelece recomendações para conservação das florestas; Convenção sobre a Diversidade Biológica, um tratado internacional multilateral para a proteção e a regulação do uso da diversidade biológica em cada país signatário (MMA, 2000), a Convenção-Quadro das Nações Unidas sobre Mudanças Climáticas, com o objetivo de estabilizar concentrações de gases de efeito estufa na atmosfera para níveis aceitáveis impedindo alterações na dinâmica do sistema climático mundial.

E por fim, também teve a confecção de um importante instrumento intitulado "Agenda 21", um plano de ação 
para a virada do século, visando a minimizar os problemas ambientais mundiais. Foi formulado internacionalmente para ser adotado em escala global, nacional e local por organizações do sistema das Nações Unidas, pelos governos e pela sociedade civil, em todas as áreas em que a ação humana impacta o meio ambiente (Lestienne, 2012).

Um denso documento com objetivos para atingir a sustentabilidade construído de forma coletiva, por isso representa o compromisso político entre todos os países signatários e integrantes da intitulada "ordem ambiental internacional" como aponta Ribeiro (1999), por estabelecer um diálogo permanente e construtivo inspirado na necessidade de atingir uma economia em nível mundial mais eficiente e equitativa.

Diretamente, propõe um processo público e participativo de planejamento e implementação de políticas para o desenvolvimento sustentável por meio da mobilização de cidadãos e cidadãs na formulação dessas políticas. Logo, pode ser considerada a mais representativa tentativa já realizada de orientação para um novo padrão de desenvolvimento no século 21, cujo fundamento é a sinergia da sustentabilidade ambiental, social e econômica, perpassando em todas as suas ações propostas, seguindo o princípio de "Pensar globalmente, agir localmente".

Diante da grandeza de seu marco e das importantes contribuições que a CNUMAD realizou na década de 1990 para a formulação de instrumentos políticos internacionais ligados às questões ambientais, fica evidente que a ordem ambiental internacional ganhou solidez em seu âmbito. Pois, a partir da repercussão e do momento em que foi realizada, tornou-se referência para as discussões das relações internacionais e do meio ambiente.

Nos anos 2000, na reunião da Cúpula do Milênio das Nações Unidas, foram traçados oito objetivos internacionais para o desenvolvimento, denominados de "Objetivos de Desenvolvimento do Milênio (ODMs)", após a adoção da Declaração do Milênio das Nações Unidas. Todos os 191 Estados membros da ONU na época e pelo menos 22 organizações internacionais, comprometeram-se em ajudar a alcançar os seguintes ODMs até 2015: Erradicar a pobreza extrema e a fome; Alcançar o ensino primário universal; Promover a igualdade de gênero e empoderar as mulheres; Reduzir a mortalidade infantil; Melhorar a saúde materna; Combater o HIV/AIDS, a malária e outras doenças; Garantir a sustentabilidade ambiental; Desenvolver uma parceria global para o desenvolvimento (UN, 2000).

Dentre essas os grandes eventos internacionais, um mais recente, realizado em 2012, a Conferência Rio+20 representou também um encontro para o estabelecimento de alianças, entre os governos de países de quase todo o planeta em torno da construção de uma nova agenda de ações para substituir os ODMs, firmados em 2000 e cujo prazo se esgotou em 2015.

Logo, a cúpula estabeleceu a criação dos Objetivos do Desenvolvimento Sustentável (ODS), aplicáveis a todos os países. Um grupo de trabalho do qual o Brasil fez parte, foi constituído em 2013 com a finalidade de apresentar propostas para a formulação dos ODS e sua entrada em vigor a partir de 2015. Os ODS foram construídos, portanto, em um processo de negociação mundial lançado em setembro de 2015, com a adesão de 193 países membros das Nações Unidas.

0 resultado desse processo foi uma lista de 17 ODS, que são acompanhados de 169 metas e 231 indicadores para avaliar a sua implementação. Esses objetivos deverão orientar as políticas nacionais e as atividades de cooperação internacional pelos próximos 15 anos, constituindo-se como uma Agenda a ser cumprida até 2030.

Em análise à evolução e relação do ambientalismo nacional e global, 
observam-se duas fases com concepções diferentes:

\begin{abstract}
A primeira fase, de 1971 a 1986, que denominaram de ambientalismo bissetorial orientado à proteção ambiental e, a segunda fase, de 1987 a 1992, definiram como ambientalismo multissetorial de transição para o desenvolvimento sustentável. 0 ambientalismo bissetorial é formado por associações e movimentos civis de meio ambiente e por técnicos e instituições ambientais governamentais. 0 ambientalismo multissetorial conjuga, além dos setores já mencionados, outros como a comunidade científica, as expressões de um sociaombientalismo e setores empresariais. Importa ainda registrar que, na primeira fase, o estado nacional ainda é o referencial principal, na formulação e gestão de políticas ambientais, enquanto, na segunda fase, a questão ambiental é mais condicionada pelo processo de globalização, porque emergem com maior força no debate os problemas ambientais globais; avança o processo de erosão dos estados e se consolida, como discurso hegemônico, a proposta de desenvolvimento sustentável (Viola e Leis, 1995; Lima, 2010).
\end{abstract}

Para Acserald (2010, p. 108), "o meio ambiente é múltiplo em qualidades socioculturais; não há ambiente sem sujeito - ou seja, ele tem distintas significações e lógicas de uso conforme os padrões das distintas sociedades e culturas". Sendo assim, é preciso reforçar a ideia de que o ambiente é um conjunto de elementos inseparáveis, que vão da paisagem até a forma de organização político-social da época.

Nesta perspectiva, Machado (2011) afirma que por se tratar de bem de uso comum de toda a população, o meio ambiente acaba sendo um bem de uso individual e coletivo, assumindo um caráter transindividual. Assim, o direito ao meio ambiente enquadra-se na categoria dos interesses difusos, configurando uma coletividade indeterminada.

Essa ideia reforça a noção de que o meio ambiente deve ser objeto de proteção tanto do Estado quanto da sociedade, para usufruto geral. Isso quer dizer que não só o Poder Público tem o dever constitucional de zelar pela defesa e pela preservação ambiental, mas também qualquer cidadão ou cidadã (Milaré, 2011).

\section{Marcos mundiais da política internacional ambiental}

Na metade da década de 1945, com o fim da Segunda Guerra Mundial, o surgimento da era nuclear fez surgir temores de um novo tipo de poluição, o por radiação. Logo, o movimento ambientalista ganhou novo impulso em 1962 com a publicação do livro de Rachel Carson, "A Primavera Silenciosa", que fez um alerta sobre o uso agrícola de pesticidas químicos sintéticos. Cientista e escritora, Carson destacou a necessidade de respeitar o ecossistema em que vivemos para proteger a saúde humana e o meio ambiente (ONU, 2015).

No final da década de 1960, dois eventos importantes marcaram o fim da época: o Pacto Internacional sobre os Direitos Humanos e a fundação do Clube de Roma. Com isso, novos ideais e visões de mundo começaram a ser discutidos e colocados em prática. Foi neste momento em que o mundo começou a adquirir uma sensibilidade maior no trato das questões ambientais. A preocupação pelo uso sustentável dos recursos ambientais se popularizou rapidamente em todo o globo. E a partir de 1972, após a Conferência das Nações Unidas sobre o Ambiente Humano, em Estocolmo (Suécia), este movimento continuou a crescer mais fortemente.

Buscando demostrar de maneira sintética o que foi esse fenômeno do pensar global ambiental, foi elaborada a Tabela 1 com os principais marcos mundiais da política ambiental. 
Tabela 1. Marcos mundiais política ambiental.

\section{SÉCULO XIX}

1869 Ernst Haeckel, propõe o vocábulo "ecologia” para os estudos das relações entre as espécies e seu ambiente.

1872 Criação da primeira Unidade de Conservação do mundo, o parque nacional "Yellowstone”, USA.

\begin{tabular}{|c|c|}
\hline \multicolumn{2}{|r|}{ SÉCULO XX } \\
\hline 1947 & Fundou-se na Suíça a UICN - União Internacional para a Conservação da Natureza \\
\hline 1952 & Big Smoke, nevoeiro tóxico provoca a morte de milhares de pessoas na cidade de Londres. \\
\hline 1962 & Publicação do livro "Primavera Silenciosa" pela bióloga marinha Rachel Carson. \\
\hline 1965 & $\begin{array}{l}\text { Pela primeira vez é utilizada a expressão “Educação Ambiental” durante a Conferência de } \\
\text { Educação da Universidade de Keele, Grã-Bretanha. }\end{array}$ \\
\hline 1966 & $\begin{array}{l}\text { Criação do Pacto Internacional sobre Direitos Civis e Políticos pela Assembleia Geral das } \\
\text { Nações Unidas }\end{array}$ \\
\hline 1968 & Fundação do Clube de Roma \\
\hline 1972 & Publicação do Relatório “Os Limites do Crescimento” pelo Clube de Roma. \\
\hline 1972 & Realização da Conferência de Estocolmo \\
\hline 1973 & Registro mundial de programas de Educação Ambiental nos Estados Unidos. \\
\hline 1974 & $\begin{array}{l}\text { O seminário de Educação Ambiental em Jammi na Finlândia, reconheceu a Educação Ambiental } \\
\text { como educação integral e permanente. }\end{array}$ \\
\hline 1975 & $\begin{array}{l}\text { Durante o Congresso de Belgrado foi construído um documento com metas e princípios da } \\
\text { Educação Ambiental. }\end{array}$ \\
\hline 1975 & Criação do Programa Internacional de Educação Ambiental - PIEA. \\
\hline 1976 & $\begin{array}{l}\text { Reunião sub-regional de EA para o ensino Secundário Chosica Peru. Questões ambientais na } \\
\text { América Latina estão ligadas às necessidades de sobrevivência e aos direitos humanos. }\end{array}$ \\
\hline 1976 & $\begin{array}{l}\text { Congresso de Educação Ambiental Brasarville, África, reconhece que a pobreza é o maior } \\
\text { problema ambiental. }\end{array}$ \\
\hline 1977 & $\begin{array}{l}\text { Conferência de Tbilisi - Geórgia, estabelece os princípios orientadores da EA e remarca seu } \\
\text { caráter interdisciplinar, critico, ético e transformador }\end{array}$ \\
\hline 1979 & Encontro Regional de Educação Ambiental para América Latina em San José, Costa Rica. \\
\hline
\end{tabular}

1980 Seminário Regional Europeu sobre EA, para Europa e América do Norte. Assinala a importância do intercâmbio de informações e experiências.

1980 Seminário Regional sobre EA nos Estados Árabes, Manama, Bahrein. UNESCO_PNUMA.

1980 Primeira Conferência Asiática sobre EA Nova Delhi, Índia 1987 Divulgação do Relatório da Comissão Brundtland, Nosso Futuro Comum

1987 Congresso Internacional da UNESCO - PNUMA sobre Educação e Formação Ambiental - Moscou. Realiza a avaliação dos avanços desde Tbilisi, reafirma os princípios de Educação Ambiental e assinala a importância e necessidade da pesquisa, e da formação em Educação Ambiental.

1988 Declaração de Caracas. ORPAL - PNUMA, Sobre Gestão Ambiental em América Denuncia a necessidade de mudar o modelo de desenvolvimento.

1989 Primeiro Seminário sobre materiais para a Educação Ambiental. ORLEAC - UNESCO - PIEA. Santiago, Chile

1989 Declaração de HAIA, preparatório da RIO 92, aponta a importância da cooperação internacional nas questões ambientais

1990 Conferência Mundial sobre Ensino para Todos, Satisfação das necessidades básicas de aprendizagem, Jomtien, Tailândia que destacou o conceito de Analfabetismo Ambiental.

1990 Ano Internacional do Meio Ambiente.

1991 Reuniões preparatórias da Rio 92.

1992 Conferencia sobre o Meio Ambiente e o Desenvolvimento, UNCED, Rio/92 - Criação da Agenda 21.

1993 Congresso Sul-americano continuidade Eco/92 - Argentina 1993 Conferência dos Direitos Humanos. Viena. 
Tabela 1. Continuação.

\begin{tabular}{|c|c|}
\hline \multicolumn{2}{|r|}{ SÉCULO XX } \\
\hline 1994 & $\begin{array}{l}\text { Conferência Mundial da População. Cairo } 1994 \text { I Congresso Ibero Americano de Educação } \\
\text { Ambiental. Guadalajara, México. }\end{array}$ \\
\hline 1995 & $\begin{array}{l}\text { Conferência para o Desenvolvimento Social. Copenhague. Criação de um ambiente econômico- } \\
\text { político-social-cultural e jurídico que permita o desenvolvimento social. }\end{array}$ \\
\hline 1995 & Conferência Mundial do Clima. Berlim \\
\hline 1996 & Conferência Habitat II em Istambul \\
\hline 1997 & II Congresso Ibero-americano de EA - Guadalajara, México. \\
\hline 1997 & Conferência sobre EA em Nova Delhi. \\
\hline 1997 & $\begin{array}{l}\text { Conferência Internacional sobre Meio Ambiente e Sociedade: Educação e Conscientização } \\
\text { Pública para a Sustentabilidade, Thessaloniki, Grécia. }\end{array}$ \\
\hline 1997 & Criação do tratado Protocolo de Kyoto \\
\hline 1999 & $\begin{array}{l}\text { Foi lançada a revista Tópicos en Educación Ambiental, uma publicação internacional editada no } \\
\text { México, que contém informações sobre as variadas vertentes e áreas da educação ambiental. }\end{array}$ \\
\hline \multicolumn{2}{|r|}{ SÉCULO XXI } \\
\hline 2002 & $\begin{array}{l}\text { Em dezembro, a Assembleia Geral das Nações Unidas, durante sua 57ạ sessão, estabeleceu a } \\
\text { resolução no 254, declarando } 2005 \text { como o início da Década da Educação para o } \\
\text { Desenvolvimento Sustentável, depositando na Unesco a responsabilidade pela implementação } \\
\text { da iniciativa. }\end{array}$ \\
\hline
\end{tabular}

2002 Cimeira Mundial sobre Desenvolvimento Sustentável: água e saneamento, energia, saúde, produtividade agrícola e biodiversidade e gestão dos ecossistemas. Joanesburgo, África do Sul.

2003 Criação da Rede Lusófona de Educação Ambiental, reunindo educadores ambientais brasileiros, portugueses e outras nacionalidades de língua portuguesa.

Criação do Programa Latino-americano e Caribenho de Educação Ambiental - PLACEA.

2005 MSI - Estratégia de Implementação das Maurícias

2010 MSI + 5 - Revisão quinquenal da Estratégia de Implementação das Maurícias

2012 Realização da Conferência das Nações Unidas sobre Desenvolvimento Sustentável, Rio + 20 Rio de Janeiro, Brasil.

2014 Terceira Conferência Internacional sobre Pequenos Estados Insulares em Desenvolvimento Apia, Samoa.

2015 Cúpula das Nações Unidas para o Desenvolvimento Sustentável 2015 - Nova Iorque, Estados Unidos.

2015 Acordo global sobre mudança do clima é adotado em Paris durante Conferência das Partes (COP-21) da Convenção-Quadro das Nações Unidas sobre Mudança do Clima (UNFCCC).

Fonte: Adaptado de Brasil, 2019.

\section{Evolução das políticas públicas ambientais no Brasil}

Atualmente, o Brasil tem um amplo sistema de gestão ambiental institucional que engloba uma série de elementos em diversas dimensões que compõem o seu aparato legal. Os instrumentos desse sistema foram criados e aperfeiçoados ao longo das épocas em diferentes momentos políticos, sociais e econômicos. Cada normativa foi criada para atender a um conjunto de interesses e necessidades que se diferenciam a depender do pensamento político-social da época.

Buscando um melhor entendimento desse sistema complexo, foi elaborada uma linha do tempo com a evolução das políticas públicas ambientais do país (Tabela 2). 
Tabela 2. Linha do tempo das políticas públicas ambientais.

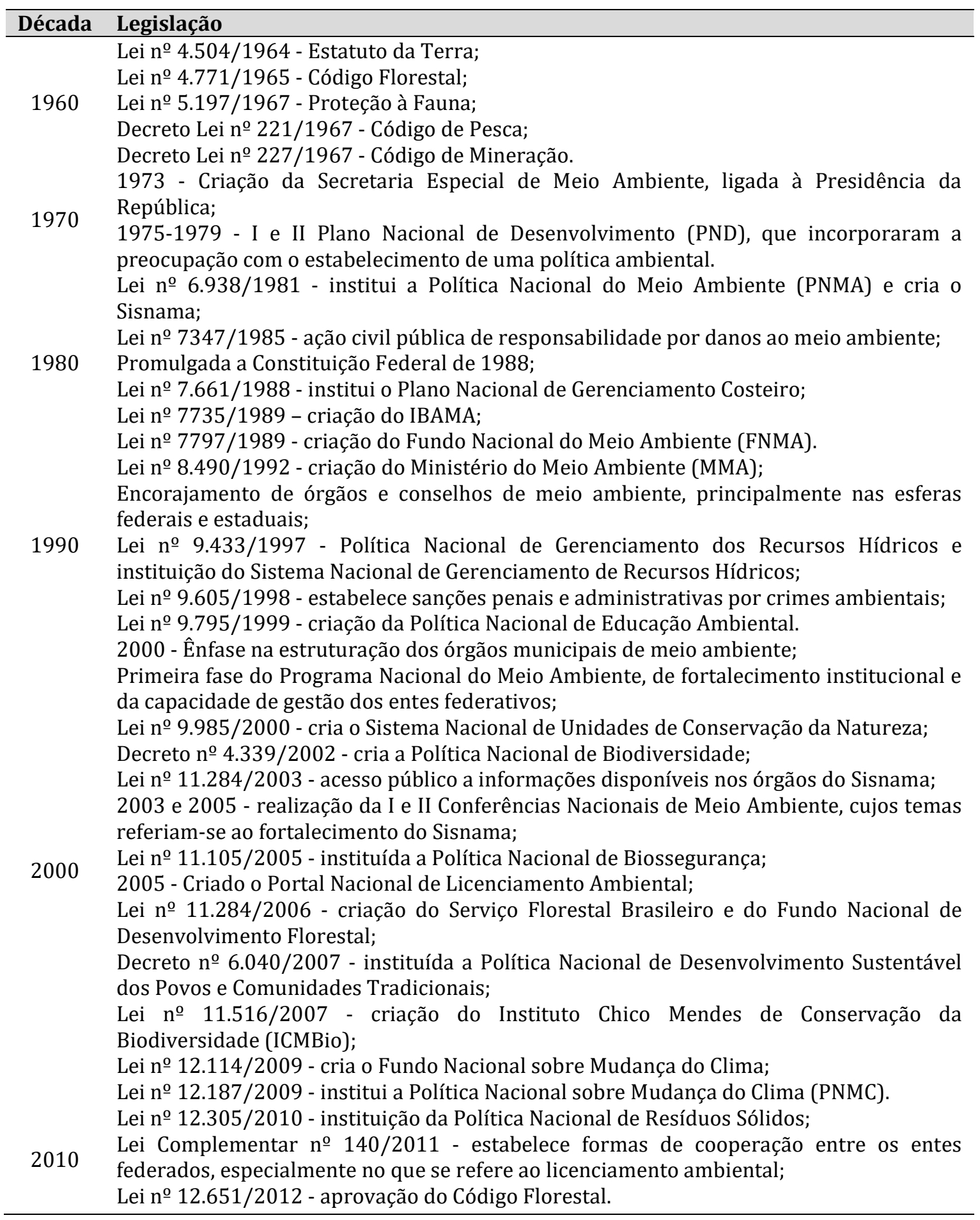

$\mathrm{Na}$ década de 1970, vários recursos ambientais em todo o planeta e no Brasil passaram a se tornar escassos. Diante desse contexto, decorreu-se o surgimento de um pensar globalizado nas questões ambientais. Alguns países criaram órgãos específicos responsáveis 
para tratar de problemas como o da poluição nos grandes centros urbanos.

$$
\text { No Brasil, apesar do }
$$

posicionamento contrário do governo em relação às discussões sobre o desenvolvimento sustentável realizadas na conferência de Estocolmo de 1972, foi criada em 1973, a Secretaria Especial do Meio Ambiente (Sema), vinculada ao Ministério do Interior responsável pela implantação de grandes projetos arquitetônicos, a exemplo da transamazônica (Viola e Leis, 1992).

No fim da mesma década, o Brasil começou a sentir as consequências econômicas, sociais e ambientais do projeto "desenvolvimento a qualquer custo". O Município de Cubatão, no Estado de São Paulo, tornou-se conhecido internacionalmente como o lugar mais poluído do mundo entre os anos de 1970 e 1980 (Silva, 2019). A população convivia com 70 tipos de poluentes no ar que formavam um imenso nevoeiro cinza na atmosfera, cujos efeitos causaram o nascimento de crianças sem cérebro. Esta situação despertou a reflexão do governo sobre os riscos iminentes do crescimento a qualquer custo (Gabinete de História, 2013).

No ano de 1975, foi publicado pelo governo federal o Decreto-Lei $\mathrm{n}$ 1.413/1975 que estabeleceu atribuições à SEMA para o controle da poluição ambiental (Brasil, 1975). Essas sucintas iniciativas do Governo Federal fomentaram a iniciativa de outros estados a criarem leis voltadas para o controle da poluição ambiental, como foram os casos do Estado do Rio de Janeiro, com o Decreto-Lei no 134/1975 (Rio de Janeiro, 1975), e de São Paulo, com a Lei no 997/1976. O grande problema é que essas iniciativas de políticas ambientais eram fundamentadas pelo princípio da correção de ações nocivas à qualidade ambiental. Outro ponto era a exclusão da participação da sociedade civil, pois o controle ambiental exercia-se por meio do entendimento do Estado e o poluidor/empreendedor.
Ao analisar a tabela, evidencia-se que a gestão ambiental no Brasil ganhou consistência há pouco mais de cinco décadas com a promulgação de leis como a de uso do solo, código florestal e proteção à fauna. Mas outro evento que se destaca, sendo muito importante para os atuais moldes da gestão ambiental brasileira, foi a criação da Política Nacional de Meio Ambiente (Lei $\mathrm{n}^{\mathrm{o}}$ $6.938 / 1981$ ) e, por conseguinte a consolidação do Sistema Nacional de Meio Ambiente (SISNAMA), que a partir do seu surgimento provocou uma culminância na elaboração de outros instrumentos e politicas especificas objetivando atender todas as demandas emergentes dentro do campo da temática ambiental no país, garantindo a participação popular da sociedade civil brasileira e consequentemente sua expansão.

A Constituição Federal de 1988, estabeleceu efetivamente o conceito de meio ambiente na legislação e o direito e o dever de todos a ter e cuidar do meio ambiente e ao acesso por uma qualidade ambiental digna. Esta ideia está expressa no art. 225, da Carta, que diz:

\begin{abstract}
Art. 225. Todos têm direito ao meio ambiente ecologicamente equilibrado, bem de uso comum do povo e essencial à sadia qualidade de vida, impondo-se ao Poder Público e à coletividade o dever de defendê-lo e preservá-lo para as presentes e futuras gerações (Brasil, 1988).
\end{abstract}

Para Milaré (2011), esse famoso trecho da constituição federal reforça a ideia de que todos devem ter acesso ao meio ambiente, mas para que se perpetue o acesso a um meio ambiente equilibrado é preciso que todos assumam sua responsabilidade na defesa, conservação e preservação ambiental.

\section{Ações governamentais e a nova política ambiental do Brasil \\ A proteção das riquezas naturais de uma nação é um requisito}


indispensável para o seu desenvolvimento. E foi isso que o Brasil conseguiu manter ao longo das últimas quatro décadas por meio da construção gradativa de um quadro regulatório rigoroso com a participação da sociedade civil e atendendo a exigências e acordos internacionais.

No entanto, a política ambiental do país vem passando por mudanças que colocam em risco o compromisso de defender e preservar o meio ambiente, estabelecido pelo o maior e mais importante instrumento político da nação, a Constituição Federal.

Observa-se na atualidade, que o país tem ido na contramão do desenvolvimento sustentável por meio de ações governamentais que retiram a autonomia, a capacidade de formulação e implementação de políticas públicas de órgãos ambientais. Acarretando em um grande retrocesso contra esforços de décadas para construção de uma governança ambiental sólida. 0 resumo dessa política de desmonte está sintetizado na Tabela 3.

Tabela 3. Ações governamentais sob a orientação da nova política ambiental.

\begin{tabular}{|c|c|c|}
\hline Ações & Instrumento & Objetivos \\
\hline $\begin{array}{l}\text { Mudanças na estrutura } \\
\text { organizacional do MMA }\end{array}$ & $\begin{array}{l}\text { MP no } 870 / 19(\text { art. } 21) \\
\text { Decreto nº } 9672 / 2019 \\
\text { Decreto no } 9667 / 2019\end{array}$ & $\begin{array}{l}\text { Extinção da Secretaria de Mudanças } \\
\text { do Clima, Secretaria de Extrativismo } \\
\text { e Desenvolvimento Rural Sustentável } \\
\text { e da Secretaria de Articulação } \\
\text { Institucional e Cidadania Ambiental; } \\
\text { Transferência da ANA, Secretaria } \\
\text { Nacional de Segurança Hídrica e } \\
\text { Conselho Nacional de Recursos } \\
\text { Hídricos para o Ministério de } \\
\text { Desenvolvimento Regional; } \\
\text { Transferência do Serviço Florestal } \\
\text { Brasileiro para o Ministério da } \\
\text { Agricultura, } \\
\text { Abastecimento (MAPA). }\end{array}$ \\
\hline & $\begin{array}{l}\text { Instrução Normativa IBAMA } \\
\text { nº 8/2019. }\end{array}$ & $\begin{array}{l}\text { Definir a delegação dos processos de } \\
\text { licenciamento ambiental a cargo do } \\
\text { Ibama. }\end{array}$ \\
\hline $\begin{array}{l}\text { Confusão na divisão das } \\
\text { competências para o } \\
\text { Licenciamento Ambiental }\end{array}$ & Decreto no 9.669/2019 & $\begin{array}{l}\text { Criação da Secretaria de Apoio ao } \\
\text { Licenciamento Ambiental e } \\
\text { Desapropriações, no âmbito da } \\
\text { Presidência da República, com } \\
\text { função de apoiar o Licenciamento } \\
\text { Ambiental de obras estratégicas do } \\
\text { Programa de Parcerias e } \\
\text { Investimentos. }\end{array}$ \\
\hline \multirow{2}{*}{$\begin{array}{l}\text { Retirada da autonomia do } \\
\text { IBAMA e ICMBio }\end{array}$} & Ofício Circular & 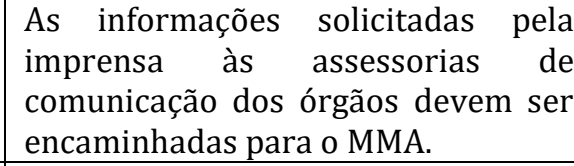 \\
\hline & $\begin{array}{l}\text { Ofício da Presidência do } \\
\text { IBAMA ao MMA }\end{array}$ & $\begin{array}{l}\text { Presidente do Ibama despreza } \\
\text { análise técnica realizada pela } \\
\text { própria equipe e autoriza exploração } \\
\text { de petróleo na região do Parque } \\
\text { Nacional de Abrolhos. }\end{array}$ \\
\hline
\end{tabular}


Tabela 3. Continuação.

\begin{tabular}{|c|c|c|}
\hline Ações & Instrumento & Objetivos \\
\hline & Decreto no 9.760/2019 & $\begin{array}{l}\text { Analisar, mudar o valor e até anular } \\
\text { cada multa aplicada pelo Ibama por } \\
\text { crimes ambientais. }\end{array}$ \\
\hline & Comunicado oficial & $\begin{array}{l}\text { Divulgação antecipada dos locais } \\
\text { onde ocorrerão as operações de } \\
\text { fiscalização na Amazônia. }\end{array}$ \\
\hline $\begin{array}{l}\text { Ataque a Política de Povos e } \\
\text { Comunidades Tradicionais }\end{array}$ & $\begin{array}{l}\text { MP no } 870 / 2019 \text { (art. } 21) \\
\text { Decreto } n^{0} 9.967 / 2019 \\
\text { Decreto } n^{0} 9.673 / 2019\end{array}$ & $\begin{array}{l}\text { Transferência da Fundação Nacional } \\
\text { do Índio (Funai) do Ministério da } \\
\text { Justiça para o Ministério da Mulher, } \\
\text { Família e Direitos Humanos; } \\
\text { Transferência da Demarcação e do } \\
\text { Licenciamento Ambiental de terras } \\
\text { indígenas da Funai para o MAPA. }\end{array}$ \\
\hline \multirow{2}{*}{$\begin{array}{l}\text { Aprovação de novos } \\
\text { agrotóxicos e } \\
\text { enfraquecimento das } \\
\text { políticas de segurança } \\
\text { alimentar e nutricional }\end{array}$} & $\begin{array}{l}\text { Atos do MAPA no } 1,7,10,17 \\
24,29,34,42 \text { e } 47\end{array}$ & $\begin{array}{l}\text { Concessão de permissão para } \\
\text { comercialização e uso de novos } \\
\text { defensivos agrícolas, totalizando } 262 \\
\text { autorizações até julho de } 2019 \text {. }\end{array}$ \\
\hline & Lei no $13.844 / 2019$ & $\begin{array}{l}\text { Extinção do Conselho Nacional de } \\
\text { Segurança Alimentar e Nutricional. }\end{array}$ \\
\hline $\begin{array}{l}\text { Revisão das Unidades de } \\
\text { Conservação Federais }\end{array}$ & $\begin{array}{l}\text { Entrevista concedida pelo } \\
\text { Ministro do MMA à imprensa }\end{array}$ & $\begin{array}{l}\text { Revisar todas as } 334 \text { Unidades de } \\
\text { Conservação Federais do país, } \\
\text { podendo mudar de categoriza ou até } \\
\text { mesmo extinguir algumas. }\end{array}$ \\
\hline Redução do Conama & Decreto no $9.806 / 2019$ & $\begin{array}{l}\text { Diminuição composição do CONAMA } \\
\text { de } 96 \text { conselheiros para } 23 \text {. } 0 \text { que } \\
\text { retira a participação de segmentos } \\
\text { importantes da sociedade civil, } \\
\text { dando grande poder ao governo } \\
\text { federal. }\end{array}$ \\
\hline $\begin{array}{l}\text { Oposição a Acordos } \\
\text { Internacionais }\end{array}$ & $\begin{array}{c}\text { Ato formalizado à } \\
\text { Organização das Nações } \\
\text { Unidas (ONU) }\end{array}$ & $\begin{array}{l}\text { Governo retirou candidatura para } \\
\text { sediar a COP-25; } \\
\text { Governo não assinou o acordo } \\
\text { mundial para limitação de resíduos } \\
\text { plásticos. }\end{array}$ \\
\hline
\end{tabular}

Fonte: Adaptado de GREENPEACE (2019).

Diante dessas ações que claramente visam ao desmonte das políticas públicas ambientais, a mais grave consequência a ser destacada na nova política ambiental adotada pela atual gestão do Governo Federal, é o enfraquecimento do Ministério do Meio Ambiente a partir de medidas que levaram a redução da pasta.

A extinção da Secretaria de Mudanças do Clima, Secretaria de Extrativismo e Desenvolvimento Rural Sustentável e da Secretaria de Articulação Institucional e Cidadania
Ambiental por exemplo, é um ataque ao protagonismo histórico do Brasil na luta contra o desafio das mudanças climáticas, causa insegurança na permanência de programas voltados para pequenos agricultores e comunidades tradicionais e prejudica a articulação política entre os entes da União, já que a última secretaria citada era responsável pela coordenação das diretrizes para elaboração, aplicação e supervisão das normas ambientais no âmbito do SISNAMA. 
Como demonstrado por Ferrante e Fearnside (2019), Pereira et al. (2019) e Diele-Viegas e Rocha (2020), estas medidas podem levar ao colapso do sistema que é constituído por órgãos e entidades da União, dos Estados, do Distrito Federal e dos Municípios que são responsáveis pela proteção ambiental (Brasil, 1981). É a estrutura adotada para a gestão ambiental no Brasil, com o objetivo de melhorar e recuperar a qualidade ambiental no país. E trata-se do mais importante instrumento de governança ambiental para orquestrar a difícil tarefa da gestão pública ambiental.

\section{Conclusões}

A questão ambiental no Brasil começou a ser debatida no final da década de 1950, estruturando-se sob um caráter preservacionista dos recursos ambientais que na época se configurava pela articulação entre dois principais grupos, as associações ambientalistas civis e as agências estatais de meio ambiente.

A partir da década de 1980, começou um movimento mais focado na participação e na opinião pública em relação às questões ambientais brasileiras. Nessa perspectiva, o movimento ambientalista brasileiro passou por transformações orientadas pelas recomendações e o conceito do "desenvolvimento sustentável" proposto pelo Relatório de Brundtland e por outros instrumentos, eventos e marcos mundiais que ocorreram mais tarde. Dentro desse contexto, a política ambiental brasileira saiu de uma configuração bissetorial preservacionista e passou a ter um caráter multissetorial agregando vários setores na participação e formulação de sua legislação.

Grande parte dos problemas ambientais do país são ocasionados por uma estrutura socioeconômica e política instituída no Brasil e que vem sendo mantida por décadas. Mesmo assim, apesar de possuir grandes problemas ambientais quando comparados a níveis mundiais, os problemas ambientais e estruturais do país ainda podem ser considerados de grau razoavelmente reversíveis.

Tais questões relacionam-se, em grande parte, com a crise ambiental no contexto urbano-rural-industrial brasileiro, por meio da poluição indiscriminada dos recursos hídricos, uso de agrotóxicos, desmatamento e emissão de gases do efeito estufa. Falta fiscalização e rigor no cumprimento das leis ambientais.

Foi constado um grande avanço das políticas ambientais do país ao longo das últimas cinco décadas, adequando-se as exigências mundiais estabelecidas em conferências de países integrantes da Organização das Nações Unidas (ONU). Contudo, esse avanço vem sendo colocado em risco devido a medidas governamentais que visam a enfraquecer a política ambiental brasileira, proporcionando maior flexibilidade para que empreendedores nacionais e internacionais explorem os recursos ambientais do país.

As últimas ações governamentais dentro do campo da política ambiental colocam em risco a governança socioambiental do país e vão contra os princípios do artigo 225 da Constituição Brasileira, que impõe ao poder público e à coletividade o dever de defender e preservar o meio ambiente. Está em curso um processo de desmonte das políticas públicas ambientais, que poderão culminar no colapso do Sistema Nacional do Meio Ambiente (SISNAMA) e certamente em desastres ambientais e impactos negativos na qualidade ambiental e de vida do povo brasileiro.

\section{Conflitos de interesse}

Os autores declaram não haver conflitos de interesse.

\section{Referências}

Acselrad, H. Ambientalização das lutas sociais: o caso do movimento por justiça 
ambiental. Estudos Avançados, v. 24, n. 68, p. 103-119, 2010. https://doi.org/10.1590/ S0103-40142010000100010

Almeida, W.; Rodrigues, D.; Santana, H. S. O posicionamento do Brasil nas negociações internacionais sobre temas de meio ambiente. Revista do Direito Público, v. 9, n. 2, p. 183-202. Disponível em: <http://www.uel.br/revistas/uel/index.php /direitopub/article/view/19519>. Acesso em: 05 nov. 2018.

Bardin, L. Análise de conteúdo. rev. e atual. Lisboa: Edições 70, 2009.

Brasil. Decreto-Lei no 1.413, de 31 de julho de 1975. Dispõe sobre o controle da poluição do meio ambiente provocada por atividades industriais. Disponível em: <http://www. planalto.gov.br/ccivil_03/Decreto-Lei/19651988/Del1413.htm>. Acesso em: 15 nov. 2018.

Brasil. Constituição da República Federativa do Brasil 1988. Disponível em: $<$ http://www.planalto.gov.br/ccivil_03/Cons tituicao/Constituicao.htm>. Acesso em: 15 nov. 2018.

Brasil. Lei no 6.938, de 31 de agosto de 1981. Dispõe sobre a Política Nacional do Meio Ambiente, seus fins e mecanismos de formulação e aplicação. Disponível em: <http://www.planalto.gov.br/ccivil_03/Leis/ L6938.htm>. Acesso em: 05 nov. 2018.

Brasil. Lei no 9.985, de 18 de julho de

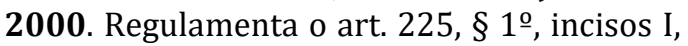
II, III e VII da Constituição Federal, institui o Sistema Nacional de Unidades de Conservação da Natureza e dá outras providências. Disponível em: <http://www. planalto.gov.br/ccivil_03/leis/19985.htm>.

Acesso em: 05 nov. 2018.

Brasil. Lei no 12.651, de 25 de maio de 2012. Dispõe sobre a proteção da vegetação nativa; altera as Leis $\mathrm{n}^{\text {os }} 6.938$, de 31 de agosto de 1981, 9.393, de 19 de dezembro de 1996, e 11.428, de 22 de dezembro de 2006; revoga as Leis nos 4.771 , de 15 de setembro de 1965, e 7.754, de 14 de abril de 1989, e a Medida Provisória no 2.166-67, de 24 de agosto de 2001; e dá outras providências.. Disponível em: <http://www.planalto.gov. br/ccivil_03/_Ato2011-2014/2012/Lei/ L12651.htm>. Acesso em: 15 nov. 2018.

Carson, R. L. Primavera silenciosa. São Paulo: Gaia, 2010.
Diele-Viegas, L. M.; Rocha, C. F. D. Why releasing mining on Amazonian indigenous lands and the advance of agrobusiness is extremely harmful for the mitigation of world's climate change? Comment on Pereira et al. (Environmental Science \& Policy 100 (2019) 8-12). Environmental Science \& Policy, v. 103, p. 30, 2020. https://doi.org/ 10.1016/j.envsci.2019.10.015

Ferrante, L.; Fearnside, P. M. Brazil's new president and 'ruralists' threaten Amazonia's environment, traditional peoples and the global climate. Environmental Conservation, v. 46, n. 4, p. 261-263, 2019. https://doi.org/10.1017/S03768929190002 13

Gabinete de História. 1972: o Brasil na Conferência de Estocolmo. 2013. Disponível em: <http://gabinetedehistoria.blogspot. com/2013/10/1972-o-brasil-na-conferen cia-de.html>. Acesso em: 15 nov. 2018.

Greenpeace. Seis meses de Bolsonaro: ataques ao meio ambiente atingem a economia. 2019. Disponível em: <https://www.greenpeace.org/brasil/blog/s eis-meses-de-bolsonaro-ataques-ao-meioambiente-atingem-a-economia/>. Acesso em: 15 out. 2018.

ISO - International Organization for Standardization. ISO 14000 family Environmental management. 2015. Disponível em: <https://www.iso.org/iso14001-environmental-management.html>. Acesso em: 15 out. 2018.

Lestienne, B. Johannesburg, ou "Rio + 10": $2^{\mathrm{a}}$ Cúpula Mundial sobre o Desenvolvimento Sustentável. 2012. Disponível em: <http://resistir.info/ambiente/johannesburg .html>. Acesso em: 15 out. 2018.

Lima, G. F. C. Gestão socioambiental: entre a técnica, a política e os conflitos sociais sobre o meio ambiente. Anais do $\mathrm{V}$ Encontro Nacional da ANPPAS, v. 4, 2010. Disponível em: <http://www.anppas.org.br/encontro5/ cd/artigos/GT3-213-149-20100809101351. pdf $>$. Acesso em: 20 nov. 2018.

Machado, P.A. L. Direito ambiental brasileiro. 21 ed. Malheiros, 2011.

Maia, J. N. Francisco de Assis. 26 ed. Belo Horizonte: Fonte Viva. 2011.

Milaré, E. Direito do ambiente: a gestão ambiental em foco - doutrina, jurisprudência, 
glossário. 7. ed. São Paulo: Revista dos Tribunais, 2011.

MMA - Ministério do Meio Ambiente. A convenção da diversidade biológica (CDB). Brasília: MMA, 2000. Disponível em: <http://www.mma.gov.br/estruturas/sbf_dp g/_arquivos/cdbport.pdf>. Acesso em: 15 nov. 2018.

MMA - Ministério do Meio Ambiente. Tabela consolidada das Unidades de Conservação. Brasília: CNUC/Ministério do Meio Ambiente, 2018. Disponível em: <http://www.mma.gov.br/images/arquivo/ 80229/CNUC_JUL18 - B_Cat.pdf>. Acesso em: 15 jul. 2018.

Motta, R. S. A regulação das emissões de gases de efeito estufa no Brasil. Brasília: IPEA, 2010. (Texto para discussão, 1492). Disponível em: <http://www.ipea.gov.br/ portal/images/stories/PDFs/TDs/td_1492.p df>. Acesso em: 05 nov. 2018.

Novaes, W. Eco-92: avanços e interrogações. Estudos avançados, v. 6, n. 15, p. 79-93, 1992. https://doi.org/10.1590/S0103-401 41992000200005

ONU - Organização das Nações Unidas. A ONU e o meio ambiente. 2015. Disponível em: $<$ https://nacoesunidas.org/acao/meioambiente/>. Acesso em: 12 nov. 2018.

Paschoaleto, A. R.; Souza, A. P. B.; Santos, J. A.; Matheus, P. D.; Lourenço, R. V. Programa das Nações Unidas: guia de estudos. Brasília: SINUS, 2014. Disponível em: <http://sinus.org.br/2014/wpcontent/uploads/2013/11/PNUMA-GuiaOnline.pdf>. Acesso em: 15 out. 2018.

Pereira, E. J. A. L.; Ferreira, P. J. S.; Ribeiro, L. C. S.; Carvalho, T. S.; Pereira, H. B. B. Policy in Brazil (2016-2019) threaten conservation of the Amazon rainforest. Environmental Science \& Policy, v. 100, p. 8-12, 2019. https://doi.org/10.1016/j.envsci.2019.06.001

PNUMA - Programa das Nações Unidades para o Meio Ambiente. Relatório do Programa das Nações Unidas para o Meio Ambiente. 2016. Disponível em: <http://web.unep.org/relatório-revelaimpactos-do-comércio-mundial-no-meioambiente>. Acesso em: 20 jul. 2018.
Ribeiro, W. C. Globalização e meioambiente: a ordem ambiental internacional. México: Observatório Geográfico América Latina, 1999.

Rio de Janeiro. Decreto-Lei no 134, de 16 de junho de 1975. Dispõe sobre a prevenção e o controle da poluição do meio ambiente no Estado do Rio de Janeiro, e dá outras providências. Disponível em: <http://alerjln1.alerj.rj.gov.br/decest.nsf/83 b1e\%2011a446ce7f7032569ba0082511c/20 e029cb4455f7dc03256b6d00638572?0penD ocument>. Acesso em: 12 nov. 2018.

Sánchez, L. E. Avaliação de impacto ambiental. São Paulo: Oficina de Textos, 2015.

São Paulo. Lei no 997, de 31 de maio de 1976. Dispõe sobre o controle da poluição do meio ambiente. Disponível em: <https://www.al.sp.gov.br/repositorio/legisl acao/lei/1976/lei-997-31.05.1976.html>.

Acesso em: 12 nov. 2018.

Silva, J. F. P. Responsabilidade social e meio ambiente: a contabilidade como ferramenta essencial ao desenvolvimento sustentável. Revista Brasileira de Gestão Ambiental e Sustentabilidade, v. 6, n. 12, p. 67-80, 2019. https://doi.org/10.21438/rbgas.061205

UN - United Nations. Report of the United Nations conference on the human environment. Stockholm: UN, 1972. Disponível em: <http://www.undocuments.net/aphe.pdf>. Acesso em: 15 out. 2018.

UN - United Nations. Resolution adopted by the General Assembly (A/RES/55/2). New York: UN, 2000. Disponível em: <http://undocs.org/A/RES/55/2>. Acesso em: 20 out. 2018.

Viola, E. J.; Leis, H. R. A evolução das políticas ambientais no Brasil, 1971-1991: do bissetorialismo preservacionista para o multissetorialismo orientado para o desenvolvimento sustentável. In: Hogan, D. J.; Vieira, P. F. Dilemas socioambientais e desenvolvimento sustentável. Campinas: Editora UNICAMP, 1995. 